\title{
Het managen van incidenten in het onderwijs
}

\section{Praktische governance-lessen op basis van een vergelijkende case analyse* $^{*}$}

Peter Siept, Dennis de Kool, Victor Bekkers, Bram Steijn \& Alex Straathof

\begin{abstract}
Bij iedere onderwijsorganisatie doen zich incidenten voor. Deze incidenten lopen soms ernstig uit de hand. Er zijn echter ook incidenten die tijdig en effectief worden aangepakt en niet uitgroeien tot echte ongelukken of zelfs misstanden. Aan de hand van zes concrete incidenten binnen het onderwijsdomein is onderzocht hoe dankzij adequaat optreden ongelukken zijn voorkomen en welke mechanismen daarbij een rol spelen.
\end{abstract}

\section{Inleiding}

Iedere organisatie wordt geconfronteerd met gebeurtenissen die het imago kunnen schaden. Deze incidenten kunnen soms een onbeheersbaar karakter krijgen. Misstanden bij organisaties als Amarantis en InHolland waren in 2013 aanleiding voor de minister van Economische Zaken om de Commissie 'Maatschappelijk verantwoord bestuur en toezicht in semipublieke sectoren' in te stellen, die onder meer de opdracht kreeg om gedragsregels op te stellen voor professioneel en ethisch verantwoord handelen van bestuurders en interne toezichthouders in de semipublieke sectoren (Commissie Behoorlijk Bestuur, 2013). De gedachte achter 'levende' gedragsregels is dat daardoor grote incidenten en misstanden tot het verleden gaan behoren. Dergelijke gedragsregels zijn in veel organisaties vertaald in codes. Zo zijn binnen alle onderwijssectoren codes (door)ontwikkeld waarin gedeelde principes, waarden en omgangsvormen zijn beschreven, bijvoorbeeld de maatschappelijke opdracht van het onderwijs, het belang van integriteit, transparantie en de scheiding van bestuur en toezicht (Vereniging Hogescholen, 2013; MBO Raad, 2014; VO Raad, 2015; PO Raad, 2017; VSNU, 2017).

In dit artikel staat de vraag centraal hoe ernstige incidenten in het onderwijsdomein voorkomen kunnen worden en welke mechanismen daarbij een rol spelen.

* Wijlen drs. Peter Siep was als onderzoeker verbonden aan Risbo. Dr. Dennis de Kool is als onderzoeker werkzaam bij Risbo. Prof.dr. Victor Bekkers is hoogleraar en decaan van de Erasmus School of Social and Behavioural Sciences (ESSB) van de Erasmus Universiteit Rotterdam. Prof.dr. Bram Steijn is als hoogleraar verbonden aan de Erasmus School of Social and Behavioural Sciences (ESSB) van de Erasmus Universiteit Rotterdam. Dr. Alex Straathof is lector Management van Cultuurverandering aan de Hogeschool van Amsterdam. Wij bedanken de directie Kennis van het ministerie van OCW, die het onderzoek heeft gefinancierd. 
In dat kader is onderzocht hoe zes verschillende onderwijsinstellingen zijn omgegaan met concrete incidenten. Een incident is in het onderzoek gedefinieerd als 'een gebeurtenis die voor de onderwijsinstelling in potentie ernstige gevolgen had kunnen hebben, welke echter door adequaat optreden niet zijn opgetreden' (Bekkers, Steijn, De Kool, Siep, Straathof \& Jansen, 2015, p. 17). Incidenten moeten dus niet worden verward met uit de hand gelopen misstanden waar bestuurders, toezichthouders en de verschillende echelons binnen de organisatie niet (tijdig) hebben ingegrepen. In andere sectoren, bijvoorbeeld in de gezondheidszorg, de chemische industrie en de luchtvaart, worden incidenten ook wel 'near misses' genoemd. In de internationale literatuur wordt benadrukt dat reflecteren op 'near misses' belangrijk is, zodat organisaties praktische lessen kunnen trekken uit de opgedane ervaringen. Dillon, Tinsley, Madsen \& Rogers (2013) benadrukken dat 'near misses' veel vaker voorkomen dan echte ongelukken. Desondanks is het binnen het (semi)publieke domein niet gebruikelijk om incidenten te onderzoeken, systematisch te registreren en hierop gezamenlijk te reflecteren.

Hoewel het onderzoek zich beperkt tot het onderwijsdomein, zijn de opzet en de bevindingen ook relevant voor andere (semi)publieke organisaties, omdat deze immers allemaal geconfronteerd worden met uiteenlopende incidenten. Het effectief managen hiervan impliceert dat organisaties toezicht, bestuur en uitvoering zodanig hebben ingericht dat voldoende snel en adequaat kan worden gereageerd op deze incidenten, zodat deze niet onbeheersbaar worden.

Eerst wordt het conceptueel model van het onderzoek nader belicht. Dit model is gebruikt bij het analyseren van de zes cases. Vervolgens worden de empirische bevindingen besproken en conclusies getrokken.

\section{Conceptueel model}

Het conceptueel model van het onderzoek bestaat uit vijf elementen die afzonderlijk zullen worden toegelicht.

\section{Samenspel tussen vier principes}

Een uitgangspunt dat is gebaseerd op literatuur over zogenoemd 'goed bestuur', is dat organisaties goed en effectief bestuurd kunnen worden wanneer sprake is van samenhang tussen principes, prestaties, processen en personen (Commissie Van Montfort, 2012; Boers \& Van Montfort, 2006; WRR, 2004). Principes zijn bijvoorbeeld transparantie, integriteit en onafhankelijkheid. Prestaties worden doorgaans gerelateerd aan de efficiënte en effectieve realisatie van doelstellingen of aan de dienstbaarheid aan het publieke belang (Commissie Behoorlijk Bestuur, 2013). Processen verwijzen naar de vormgeving van procedures en omgangsvormen die belangrijk worden geacht om behoorlijk bestuur te realiseren, bijvoorbeeld het ontwikkelen van besluitvormingsprocessen die bijdragen aan de noodzakelijke scheiding tussen bestuur en toezicht (Onderwijsraad, 2004; Commissie Governance Code BVE, 2008; Inspectie van het Onderwijs, 2016). Daarnaast is het voeren van een 'horizontale dialoog' een belangrijk proces, omdat bestuurders 
hiermee een goed beeld verkrijgen van de wensen, behoeften en zorgen die belanghebbenden ervaren (Algemene Rekenkamer, 2006). Deze horizontale dialoog kan echter geen vervanging zijn van het verticale toezicht (Onderwijsraad, 2006). Ten slotte zijn het vaak personen die het verschil kunnen maken tussen goed gedrag en wangedrag. Leiderschap speelt daarbij een belangrijke rol. Daarbij kan worden gedacht aan moreel, professioneel, integer en rechtmatig handelen (Commissie Behoorlijk Bestuur, 2013; Onderwijsraad, 2013). Verder spelen institutionele en culturele factoren een belangrijke rol (WRR, 2004; RMO, 2011; Commissie Van Montfort, 2012). Omdat de contexten waarbinnen incidenten optreden steeds uniek zijn, moet er binnen de organisatie dus een zekere improvisatieruimte zijn, omdat statische blauwdrukken niet volstaan.

\section{Interne en externe sturing}

Processen en procedures die verwijzen naar goed bestuur, krijgen vorm binnen sturingsrelaties. Voor (semi)publieke instellingen, waaronder onderwijsinstellingen, zijn twee sturingsrelaties van belang. De interne dimensie betreft het sturingsmodel dat binnen de organisatie wordt gehanteerd om de verschillende afdelingen aan te sturen en de instrumenten die daarbij worden ingezet. Daarnaast betreft het interne sturingsmodel ook de wijze waarop het bestuur en het management van een onderwijsinstelling zich willen verhouden tot relevante belanghebbende partijen binnen de instelling, waaronder de medezeggenschapsraad en ouders. Niet voor niets wordt in het onderwijsveld vaak gesproken over het belang van 'educational governance' (Strikwerda, 2005; Burns, Köster, \& Fuster, 2016). Ten tweede is er de externe dimensie. Dit betreft het 'governance'model dat ten grondslag ligt aan de relatie tussen de onderwijsinstellingen en het ministerie van OCW, inclusief de onderwijsinspectie. Grosso modo kan hier worden gesteld dat deze sturingsrelatie gekenmerkt wordt door sturing op in- en outputparameters, waaronder budgetfinanciering en de kwaliteit van het onderwijs.

\section{De invloed van de omgeving}

Het besturen van een onderwijsinstelling speelt zich niet in een vacuüm af. Omgevingsontwikkelingen zijn van invloed op de cultuur van en het feitelijke gedrag binnen onderwijsinstellingen. Relevante ontwikkelingen zijn bijvoorbeeld schaalvergroting, de discussie over nut en noodzaak van prestatiesturing, de toegenomen mondigheid van ouders en leerlingen, en de toegenomen politisering van het onderwijsveld, waarbij discussies over de kwaliteit van het onderwijs een belangrijke rol spelen (Commissie Parlementair Onderzoek Onderwijsvernieuwingen, 2008; Onderwijsraad, 2014). De laatste en niet onbelangrijkste ontwikkeling is medialisering, waarbij ook sociale media een belangrijke rol spelen.

\section{Cultuur en gedrag}

Een relevant aandachtspunt is de wijze waarop de formeel vastgelegde waarden en principes in de organisatie daadwerkelijk doorwerken in het gedrag van mensen die deel uitmaken van instellingen. Wij gebruiken het zogenaamde cultuurarenamodel om dit in kaart te brengen (Straathof, 2009). In dit model worden drie lagen onderscheiden, namelijk arena, mindset en gedrag. De arena verwijst 


\section{Figuur 1 Conceptueel model}

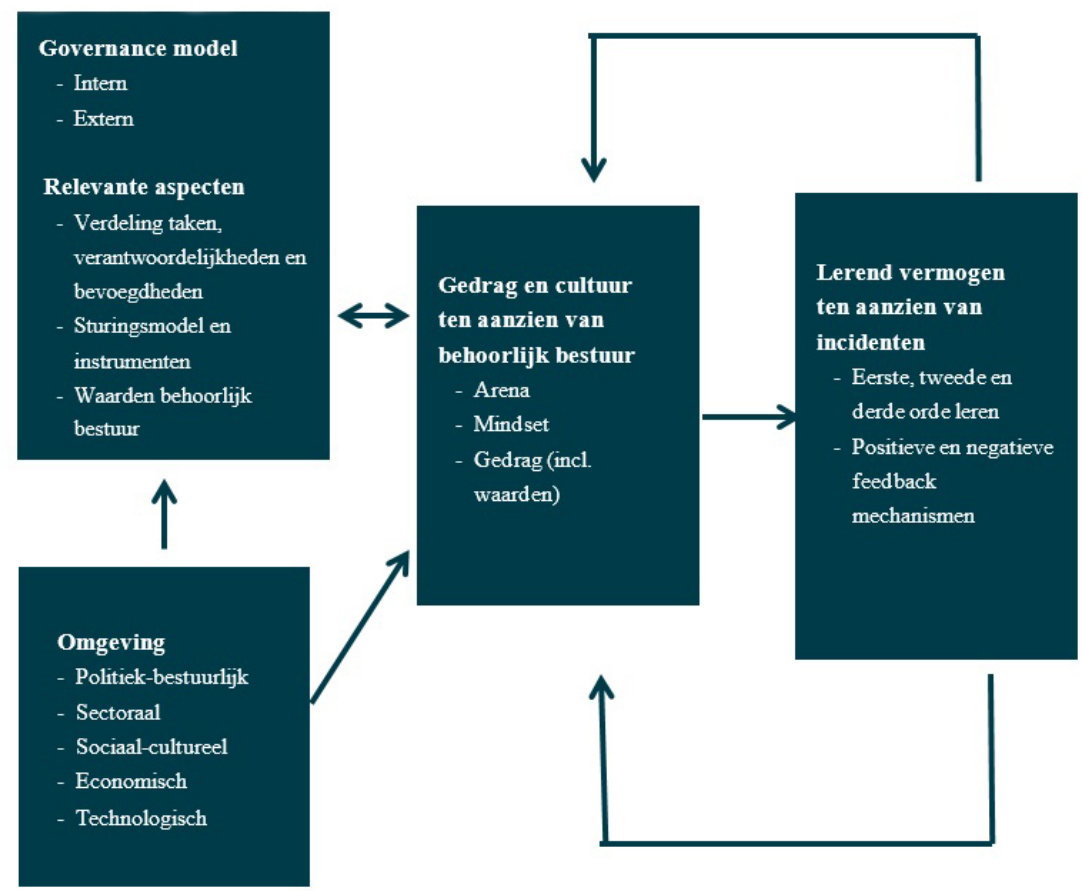

naar het geheel van onderlinge betrekkingen tussen de medewerkers van de onderwijsinstelling. Hierbij draait het om informele macht en invloed. De mindset betreft de opvattingen die mensen binnen een organisatie met elkaar gemeen hebben. Gedrag omvat het feitelijke gedrag van de organisatieleden.

\section{Lerend vermogen}

Elk incident kan in principe bijdragen aan het versterken van het leervermogen van een organisatie, waardoor soortgelijke of verwante gebeurtenissen in de toekomst kunnen worden voorkomen. Een organisatie waarin men gericht is op het vroegtijdig onderkennen en het zo snel mogelijk corrigeren van situaties die uit de hand dreigen te lopen, staat en valt dus met het idee dat er sprake is van een 'lerende organisatie'. Essentieel voor een dergelijke lerende organisatie is de aandacht die gegeven wordt aan feedbackprocessen (Senge, 1990).

Bovenstaande elementen zijn opgenomen in een conceptueel model over hoe organisaties met een incident kunnen omgaan (zie figuur 1). De redeneerlijn in dit model is dat gedragingen van de belanghebbende partijen in en rondom de organisatie die wordt geconfronteerd met een incident, worden beïnvloed door het interne en externe sturingsmodel, het samenspel tussen personen, principes, processen en prestaties, specifieke omgevingsfactoren, en de cultuur (gedragsoplossingen, mindset en machtsverhoudingen) van de organisatie. Gedrag wordt 
ook beïnvloed door eerdere ervaringen met incidenten die hebben geleid tot een bepaald lerend vermogen.

\section{Empirische bevindingen}

Ten behoeve van het onderzoek zijn zes cases onderzocht, waarbij is gedifferentieerd naar verschillende soorten van incidenten binnen alle onderwijssectoren (externe ontwikkelingen, financiën, onderwijskwaliteit, sociale veiligheid en administratieve processen). Per casus is een achtergrondstudie verricht op basis van documenten en interviews met relevante stakeholders, zoals bestuur, toezicht, middenmanagement, medewerkers op de werkvloer en medezeggenschap. Daarna is een vergelijkende analyse van de cases gemaakt. Ter validering van de bevindingen zijn expertmeetings georganiseerd en is een workshop verzorgd. Deze gekozen opzet heeft uiteraard beperkingen. De aard van dit onderzoek stond vooral in het teken van 'analytische generaliseerbaarheid' en richtte zich op het verkrijgen van inzicht in achterliggende mechanismen die een rol spelen bij het omgaan van organisaties met incidenten. Het onderzoek laat daarmee de plausibiliteit van de achterliggende mechanismen zien (Yin, 2003) en beoogt geen toetsing van het conceptuele model.

\section{Casus bevolkingskrimp}

Stichting INNOVO is een grote instelling voor primair onderwijs in de krimpregio Zuid- en Midden-Limburg. Het incident betreft de wijze waarop deze stichting omgaat met de demografische realiteit van 'bevolkingskrimp' en de fusies en eventuele sluitingen van basisscholen die daar het gevolg van (kunnen) zijn. De dreigende sluiting van scholen in een gebied met veel kleine woonkernen ligt immers gevoelig en roept grote emoties in de betrokken gemeenschappen op. Om hier beter mee om te kunnen gaan, introduceerde de nieuwe bestuursvoorzitter een andere bestuursstijl. Waar in de oude stijl vooral de nadruk lag op 'zenden', wordt nu een bottom-up aanpak gehanteerd, waarbij alle relevante belanghebbende partijen worden betrokken en een actieve rol krijgen toebedeeld. Diverse scenario's worden bijvoorbeeld gezamenlijk ontwikkeld. Het nadenken over de toekomst van specifieke scholen wordt benaderd als een organisch proces. De gehanteerde uitgangspunten zijn heldere procesafspraken, transparante procedures en het delen van zo veel mogelijk informatie. Bij eventuele sluitingen en fusies van scholen vervullen de bestuurders en de betrokken directeur(en) een belangrijke rol bij het managen van de 'emoties' die vrijkomen.

\section{Casus onderwijskwaliteit}

Het Arentheem College in Arnhem bestaat uit drie scholen voor het voortgezet onderwijs. De casus speelde op een vwo-afdeling van dit college. Het incident betreft het feit dat de onderwijsinspectie de leeropbrengsten van één afdeling als onvoldoende beoordeelde. Dit oordeel kan op termijn onder andere impact hebben op het imago van de school, de motivatie van het betreffende docententeam en het aantal aanmeldingen van nieuwe leerlingen. Bovendien was het inspectie- 
oordeel niet te rijmen met waar de school voor staat. Volgens de onderwijsinspectie was het onderwijsproces wel op orde en heerste er een prettig schoolklimaat. Ook werd het kwaliteitsbeleid van de instelling als voldoende beoordeeld. De school werd op basis van dit oordeel onder intensief toezicht geplaatst. De (bovenschoolse) centrale directie is toen krachtig gaan sturen richting de locatiedirectie om verbetering te bereiken. De komst van een nieuwe locatiedirectie zorgde daarbij voor nieuw elan. Medewerkers van de betreffende locatie werden actief bij de verbeterplannen betrokken. Uit een zelfanalyse van de school bleek dat er in de oude situatie te veel nadruk werd gelegd op buitenschoolse activiteiten. Dat ging ten koste van de onderwijsprestaties van leerlingen. De genomen maatregelen waren succesvol, want twee jaar later werden de onderwijsopbrengsten door de onderwijsinspectie weer als voldoende beoordeeld.

\section{Casus wapenincident}

Op een locatie van ROC Mondriaan in Delft deed zich een wapenincident voor. Een buurtbewoner meldde aan de politie dat een leerling buiten de school een wapen toonde aan enkele medeleerlingen. De betrokken leerling ging vervolgens het gebouw in. Het was onduidelijk of hij toen het wapen nog bij zich droeg. Na de melding nam de politie, in nauw overleg met de school, de regie in handen vanwege de aard van het incident. Besloten werd om het gebouw te ontruimen. Dankzij sociale media bleken leerlingen en ouders eerder op de hoogte van de situatie dan de docenten in de klassen. Ook traditionele media kwamen in actie. De betrokken leerling kon worden aangehouden door het door de politie ingezette arrestatieteam, maar bleek geen kwade bedoelingen te hebben. $\mathrm{Na}$ afloop werden de ouders en leerlingen geïnformeerd. De betreffende scholier is naar een andere school gegaan en uit de evaluatie van de gang van zaken bleek dat het incident ondanks de goede afloop een grote impact had op de veiligheidsbeleving van medewerkers en dat zij behoefte hadden aan (meer) nazorg om het incident te verwerken.

\section{Casus examenfraude}

Het ROC van Amsterdam is een instelling die bestaat uit negen verschillende mbo-colleges. Het incident betreft een anonieme melding van examenfraude bij één mbo-college. Toen duidelijk werd dat toetsvragen vooraf waren uitgelekt, werd de betreffende tentamenuitslag ongeldig verklaard. De onderwijsinspectie en de politie werden geïnformeerd. Ook werd een recherchebureau ingeschakeld om de kwestie te onderzoeken. De instelling heeft bewust gekozen voor een open communicatiestrategie richting studenten en hun ouders in de vorm van een brief. Voor de medewerkers werd op intranet een logboek bijgehouden. Ook de media werden te woord gestaan op de dag dat de kwestie in de publiciteit kwam. Daarna werd een 'radiostilte' afgekondigd in afwachting van het onderzoek. Veel later bleek dat er sprake was van diefstal van tentamens. De aandacht van de media was toen reeds gericht op andere kwesties. 


\section{Casus vermeende examenfraude}

De Haagse Hogeschool is een instelling voor hoger onderwijs. Het incident betreft een vermeende examenfraude bij een academie van deze instelling die structureel van aard zou zijn. De melding was afkomstig van een journalist die aanwijzingen zou hebben dat sprake was van systematische en langdurige fraude binnen één specifieke opleiding. De instelling heeft toen een regie- en kernteam geformeerd en de processen rondom tentamens grondig tegen het licht gehouden. Ook werd een recherchebureau ingeschakeld om de zaak uit te zoeken. Alle betrokken partijen werden direct geïnformeerd over de vermeende fraude. De kwestie kreeg veel aandacht in de media. Ondanks het uitvoerige onderzoek van het recherchebureau konden geen bewijzen van systematische fraude worden gevonden. Op basis van het onderzoek zijn procedures aangescherpt en is meer bewustwording ontstaan bij medewerkers over de gevaren en effecten van deze vorm van fraude.

\section{Casus financiële problemen}

De universiteit van Maastricht werd geconfronteerd met een groot financieel tekort bij een specifiek en relatief klein organisatieonderdeel. Vanaf de oprichting was ingezet op het neerzetten van een kwalitatief hoogstaande graduate school. Uit een lovend visitatierapport bleek dat de inhoudelijke en wetenschappelijke ambities werden waargemaakt. Minder oog was er echter voor de bedrijfsvoering. Bovendien werd het organisatieonderdeel geconfronteerd met een financiële tegenvaller. Dit resulteerde uiteindelijk in een miljoenentekort, waarna het college van bestuur besloot om in te grijpen en de graduate school onder curatele stelde. Het zoeken naar een oplossing heeft enige tijd geduurd, omdat de betrokken stakeholders verschillende inzichten en belangen hadden. Destijds werden persoonlijke conflicten ook in de lokale media uitgevochten en dat heeft zijn sporen nagelaten. Uiteindelijk werd een oplossing gevonden. De graduate school werd bij een ander organisatieonderdeel ondergebracht, waardoor in korte tijd aanzienlijke kostenbesparingen konden worden gerealiseerd. Een deel van het personeel is intern herplaatst. De graduate school wist, ondanks de perikelen, haar goede wetenschappelijke reputatie te behouden.

\section{Analyse en conclusies}

Als we de cases naast elkaar zetten, kunnen aan de hand van het conceptuele model een aantal conclusies worden getrokken over wat organisaties kunnen doen om te voorkomen dat incidenten zich ontwikkelen tot echte ongelukken.

\section{Omgeving: politisering en medialisering}

Wat betreft de omgevingsfactoren geldt voor alle casussen, met uitzondering van de universiteitscasus, dat het incident zich manifesteert in een gepolitiseerde context. De kwaliteit en toegankelijkheid van het onderwijs en de veiligheid op scholen zijn relevante maatschappelijke zorgen. Incidenten op dat vlak zijn dus verzekerd van politieke, publieke en media-aandacht. Vandaar dat de omgeving van onderwijsinstellingen ook in hoge mate gemedialiseerd is. Zeker met de 
opkomst van sociale media kunnen incidenten snel veel aandacht krijgen. Dat werd bijvoorbeeld zichtbaar bij het wapenincident, waarbij leerlingen en ouders dankzij sociale media en ondanks 'radiostilte' eerder op de hoogte waren dan de docenten die voor de klas stonden.

Dit impliceert dat bij incidenten binnen onderwijsinstellingen doorgaans snel gehandeld en geschakeld moet worden. Dit stelt hoge eisen aan de communicatiestrategie van de betreffende instelling, die verder reikt dan 'uitleg' geven. Bij het omgaan met incidenten is daarom een vorm van 'strategic issue management' vereist (Bekkers, Beunders, Edwards \& Moody, 2009; Heath \& Palenchar, 2009). De bestudeerde cases laten in dat kader zien hoe belangrijk het is om transparant te zijn en verantwoording af te leggen tegenover de buitenwacht.

\section{Governance-structuur}

De (interne) governance-structuur van de instelling doet er blijkens ons onderzoek meer toe dan de externe governance-relaties met bijvoorbeeld het ministerie van OCW of gemeenten. Een patroon dat zich aftekent, is dat het succesvol omgaan met incidenten lijkt samen te hangen met het bestaan van een heldere taak- en rolverdeling van het college van bestuur, raad van toezicht, lokale directies en communicatieafdelingen. Tevens is sprake van een regelmatige dialoog met alle interne en externe stakeholders, waardoor bij een incident een beroep kan worden gedaan op elkaar kennen, elkaar weten te vinden en ook elkaar weten te vertrouwen.

De regievoering kan per incident variëren. Bij het wapenincident nam de politie vanzelfsprekend de regie op zich. Bij de andere incidenten is soms centrale regie onvermijdelijk (bijvoorbeeld bij de universiteitscasus), maar bij andere cases werd de regie bewust op decentraal niveau belegd (bijvoorbeeld bij de beide examenfraude-cases). In dat laatste geval moet de governance-structuur ruimte bieden voor lokale autonomie, maar wel in het licht van een heldere taakverdeling.

De mate waarin de RvT een rol speelt, verschilt per casus. Dat heeft mede te maken met de variatie van de cases. Toch tekent zich ook hier een patroon af. In een aantal gevallen speelt de RvT niet of nauwelijks een actieve rol en wordt deze vooral achteraf geïnformeerd. In een enkel geval (casus hogeschool en universiteit) worden interventies echter wel in nauwe samenspraak met de RvT gedaan. Dit hangt onder meer samen met de interne taakverdeling en rolopvatting van de besturen en de raden van toezicht en de daarmee samenhangende wijze van communiceren.

De code goed bestuur die handelingsrichtlijnen bevat voor het omgaan met incidenten, speelt blijkens het onderzoek slechts op de achtergrond een rol. Dit betekent niet dat de code overbodig is. Direct betrokkenen verwijzen in interviews naar waarden en principes maar deze relateren ze zelf niet expliciet aan de code. Desondanks wordt 'in de geest van de code' gehandeld. In die zin handelt men dus 'onbewust bekwaam'. 


\section{Cultuur en gedrag}

Alle onderzochte instellingen kennen een gefragmenteerde cultuur en bestaan in feite uit een groot aantal afzonderlijke eenheden met veelal een eigen deelcultuur. Dit staat echter het ontstaan van succesvolle samenwerking bij het omgaan met het incident niet in de weg. Hetzelfde geldt voor de grote afstand die veelal wordt ervaren tussen de werkvloer en de centrale directie of het bestuur. Dit lijkt in de cases geen probleem zolang er binnen het lokaal niveau maar saamhorigheid ontstaat, en er vervolgens 'alignment' tussen het lokale en centrale bestuur bestaat. De maatschappelijke opdracht van onderwijsinstellingen maakt dat het oplossen van incidenten wordt beleefd als een gedeelde opgave en brengt deze verbinding tot stand. Verder is zichtbaar dat binnen de organisatie-eenheden waar het incident optreedt de hiërarchie steeds relatief gering is en de communicatielijnen kort zijn. In die zin lijkt het door verschillende instellingen uitgedragen principe van 'klein binnen groot' een rol te spelen. Dit principe kan een verklaring bieden voor het feit dat de omvang van onderwijsinstellingen als zodanig geen rol speelt bij het vermogen om succesvol met een incident om te gaan.

Effectieve samenwerking tussen verschillende niveaus in de organisatie is noodzakelijk voor het oplossen van incidenten. De succesvolle aanpak van incidenten is mensenwerk, waarbij doorgaans geen 'blauwdrukken' voorhanden zijn. Belangrijk is daarom dat men op de werkvloer de ruimte krijgt om incidenten samen aan te pakken en dat het bestuur de verbinding zoekt, openheid geeft, een voorbeeldrol vervult door zichtbaar te zijn en vertrouwen heeft in de professionaliteit van medewerkers.

\section{Lerend vermogen}

Heel nadrukkelijk worden er in de bestudeerde cases lessen getrokken uit de incidenten. Er wordt reflectie georganiseerd door middel van bijvoorbeeld evaluaties, zelfanalyses en werkgroepen. Procedures, protocollen, draaiboeken en crisisplannen zijn kritisch tegen het licht gehouden en daar waar nodig aangepast. De vraag is echter wel hoe de getrokken lessen worden geborgd. We zien namelijk dat die borging overwegend selectief is en zich vooral richt op vormen van corrigerend leren ('single loop learning'), namelijk het opnieuw tegen het licht houden van bestaande procedures, routines, systemen en werkwijzen, alsmede de positie van bestaande afdelingen om vervolgens bestaande routines, procedures en werkwijzen aan te scherpen of nieuwe aanvullende procedures in het leven te roepen en medewerkers daar vervolgens op te wijzen. Ons inziens moet worden gewaakt voor een bureaucratisering van risico's, omdat dan blikvernauwing kan ontstaan. Ieder incident is uniek en vereist een flexibel improvisatievermogen dat niet altijd in 'statische' protocollen of codes is te vangen.

\section{Belang van open dialoog}

Bij alle cases zijn onderwijsinstellingen geconfronteerd met gebeurtenissen die in potentie de legitimiteit en de continuiteit van de instelling zouden hebben kunnen schaden, bijvoorbeeld omdat vraagtekens konden worden gesteld bij de kwaliteit van het onderwijs, de administratieve procedures of de sociale veiligheid op 
school. Het onderkennen van de strategische betekenis van een incident is een noodzakelijke voorwaarde om proactief te kunnen reageren. Incidenten zijn in de dagelijkse bestuurspraktijk vaak onvermijdelijk. De bestudeerde cases laten zien dat passende interventies de schade kunnen beperken, zodat incidenten niet uitmonden in onbeheersbare situaties. Organisaties kunnen en moeten lessen trekken uit incidenten, omdat hun legitimiteit op het spel kan staan. Dit leervermogen is ook van belang in het kader van het streven naar 'behoorlijk bestuur', waaraan in een open dialoog tussen alle betrokken stakeholders vorm en inhoud gegeven wordt.

\section{Literatuur}

Algemene Rekenkamer. (2006). Goed bestuur tussen publiek en privaat. Den Haag.

Bekkers, V.J.J.M., Beunders, H., Edwards, A., \& Moody, R. (2009). De virtuele lont in het kruitvat: Welke rol spelen de oude en nieuwe media in de micromobilisatie van burgers en hun strijd om politieke aandacht? Den Haag: LEMMA.

Bekkers, V.J.J.M., A.J. Steijn, D. de Kool, P. Siep, A.J.M. Straathof \& M. Jansen (2015) Behoorlijk Bestuur van Onderwijsinstellingen, Rotterdam/Amsterdam: Erasmus Universiteit Rotterdam en Hogeschool van Amsterdam.

Boers, I., \& Montfort, C. van. (2006). Goed bestuur in governancecodes: Een vergelijking in tien verschillende branches. Goed Bestuur, 2(4), 45-51.

Burns, T., Köster, F., \& Fuster, M. (2016). Education governance in action: Lessons from case studies. Paris: OECD Publishing.

Commissie Parlementair Onderzoek Onderwijsvernieuwingen. (2008). Tijd voor Onderwijs. Den Haag (commissie Dijsselbloem).

Commissie Behoorlijk Bestuur. (2013). Een lastig gesprek. Den Haag (commissie Halsema).

Dillon, R.L., Tinsley, C.H., Madsen, P.M., \& Rogers, E.W. (2013). Organizational correctives for improving recognition of near-miss events. Journal of Management, 42(3), 1-27, doi:10.1177/0149206313498905

Evaluatiecommissie Branchecode governance hbo. (2012). Goed bestuur in het HBO. Den Haag (commissie Van Montfort).

Heath, R., \& Palenchar, L. (2009). Strategic issues management. Thousand Oaks: Sage.

Inspectie van het Onderwijs. (2016). Verantwoording over goed bestuur in het funderend onderwijs: Verkennend onderzoek naar verantwoording over wettelijke vereisten voor goed bestuur in jaarverslagen in het funderend onderwijs. Utrecht.

MBO Raad. (2014). Branchecode goed bestuur in het MBO. Woerden.

Onafhankelijke Commissie Governance Code BVE. (2008). Goed bestuur in het mbo. Den Haag.

Onderwijsraad. (2004). Degelijk onderwijsbestuur. Den Haag.

Onderwijsraad. (2006). Duurzame onderwijsrelaties. Den Haag.

Onderwijsraad. (2013). Publieke belangen dienen: Naar bestuurlijk evenwicht tussen overheid en onderwijsinstellingen. Den Haag.

Onderwijsraad. (2014) Onderwijspolitiek na de Commissie Dijsselbloem, Den Haag.

PO Raad. (2017). Code Goed Bestuur in het primair onderwijs. Utrecht.

Raad voor Maatschappelijke Ontwikkeling (RMO). (2011). Tegenkracht organiseren: lessen uit de kredietcrisis. Den Haag.

Senge, P. (1990). The fifth discipline: The art and practice of the learning organization. Boston: MIT Press. 
Straathof, A. (2009). Zoeken naar de kern van cultuurverandering: inzicht, meten en sturen. Delft: Eburon.

Strikwerda, J. (2005). Goed bestuur van onderwijs: Principes voor educational governance. In F.H.J.G. Brekelmans, P.W.A. Huisman, \& J.M.M. van de Ven (red.), Educational Governance: Symposiumbundel Nederlandse Vereniging voor Onderwijsrecht 2004 (Vol. 24, pp. 17-34). Den Haag: Sdu.

Vereniging Hogescholen. (2013). Branchecode goed bestuur hogescholen. Den Haag. VO Raad. (2015). Code Goed Onderwijsbestuur VO. Utrecht.

VSNU. (2017). Code goed bestuur universiteiten. Den Haag.

WRR. (2001). Ontwikkelingsbeleid en goed bestuur. Den Haag

WRR. (2004). Ruimte voor goed bestuur: Tussen prestatie, proces en principe. Den Haag. Yin, R. (2003). Case study research. Thousand Oaks: Sage. 